\title{
The Way to Detection of
}

Software Emergent Properties

\section{Tetiana Hovorushchenko,}

Doctor, Senior Researcher, Associate Professor, Lecturer of System Programming Department, Khmelnitsky National University

\section{Oksana Pomorova,}

Full Doctor, Professor, Head of System Programming Department, Khmelnitsky National University 


\section{Plan of Report}

1. Introduction: Actuality of Research; Research Purpose

2. Emergent properties and consequences of their display for the software. Approaches to detection of emergent properties of software systems

3. Software quality models

4. The share of non-functional requirements in the software quality models

5. Impact of the subject domain information on the knowledge gap size

6. Conclusions

7. Questions \& Discussion 


\section{Introduction: Actuality of Research;}

\section{Research Purpose}

The software quality is essential factor for its successful implementation and exploitation. The modern software is not ideal in terms of its quality.

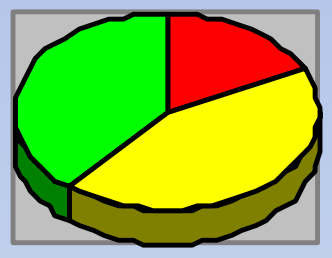

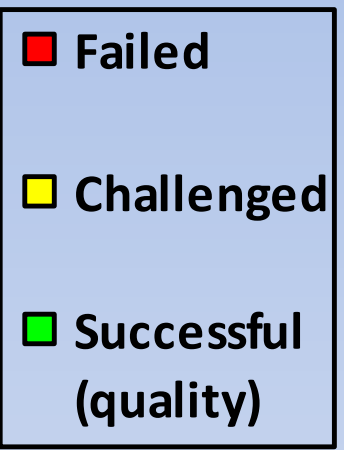

According to the modern definition of quality (as the extent of compliance the present characteristics and requirements [SWEBOK'2014]), only $39 \%$ software projects are quality.

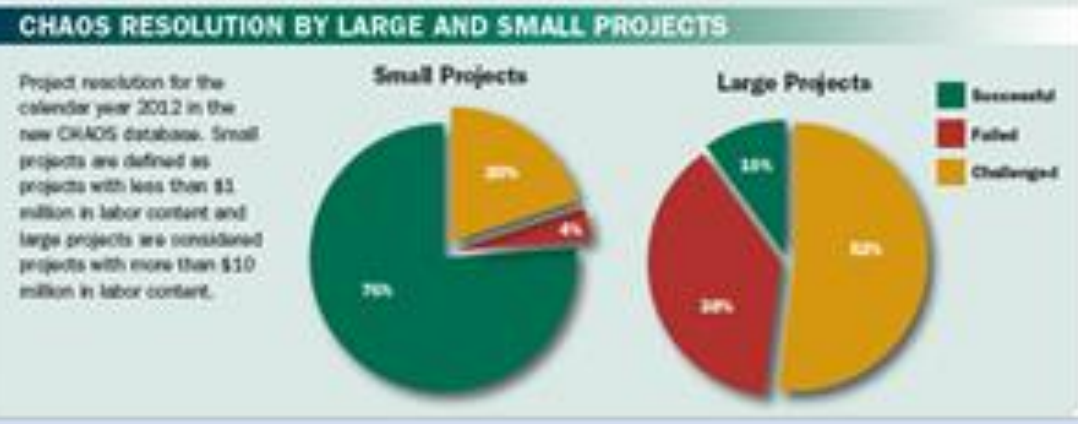

According CHAOS Manifesto report, $76 \%$ small projects are quality, but only $10 \%$ large projects are quality.

The most significant cause of the low quality of the large software projects - is the increasing of the number of components (subsystems) and interfaces between them [CHAOS Manifesto report, The Standish Group International]. 
The next causes of the low software quality:

1) uncontrolled complexity;

2) weakly consideration of the systemic aspect of modern software by the software quality models and methodologies: the insufficient attention to software emergent properties (integral feature of the system);

3) the insufficient attention to the subject domain information at the different stages of the software life cycle.

The research purposes are:

1) the detection of imperfections of the software quality evaluation (by the insufficient attention to the software emergent properties detection, evaluation and prediction; by the insufficient attention to the subject domain information during the software life cycle);

2) the analysis of the known approaches of the software emergent properties detection by the use of the software quality models;

3) the analysis of the ability of consideration and evaluation of the nonfunctional requirements in the software quality models 


\section{Emergent properties and consequences}

\section{of their display for the software}

\section{Definition of the terms "emergent property", "emergent behavior"}

An emergent property is any characteristic of a system that cannot be localized to a single independently acting constituent or to a small constant number of constituents. Emergent properties arise from the cumulative effects of the local actions and neighbor interactions of many autonomous entities.

Complex systems often exhibit properties that are not easily predictable by analyzing the behavior of their individual, interacting components. These properties, called emergent properties, are increasingly becoming important as software systems grow in complexity, coupling, and geographic distribution

The emergent properties are the divergence between intended and realized design. These properties cannot be known a priori.

Quality attributes of software will often require putting a number of functions together (i.e. emergent properties)

Emergent properties are characteristic of complex systems. Systems of sufficient complexity with typically have properties that can't be explained by breaking the system down into its elements (emergent properties)
Authors

Definition of the terms "emergent property", "emergent behavior"

The emergent properties of the collective whole do not in any transparent way derive from the underlying rules governing the

David A.

Fisher

C.Szabo,

Y.M.Teo

I.Alison,

Y.Merali

P.Kashfi

and

other

S.Kaisler, G.Madey

Complex systems often behave in unexpected ways that are not easily components - emergent behavior interaction of the system's components

Properties of the whole that are the result of interaction of the parts, or that are the result of addressing the collection of parts as a whole, are emergent properties. Emergent properties derive from the combination of constituent parts of systems

Emergent properties of software are requirements that cannot be addressed by a all the software components interoperate. Emergent properties are crucially dependent on the system architecture

Emergent properties can be thought of as unexpected behaviors that stem from interaction between the components of an application and their environment. There is considerable disagreement about the nature of emergent properties: any unexpected properties exhibited by a complex system; or an application exhibits behaviors that cannot be identified through functional decomposition.
Author

\section{Definition of the terms "emergent} property", "emergent behavior"

Author

Certain behaviors of a system of systems

G.Marsh single component but that depend on how

C.W.Johnson

Jeffrey C. Mogul arise from the interactions among the individual systems and are not embodied in any of the individual systems - emergent behavior

Emergent behavior is that which cannot be predicted through analysis at any level simpler than that of the system as a whole. Emergent behavior is what's left after everything else has been explained

Emergent behaviors are characteristics that arise from the cumulative actions and interactions of the constituents of a system-of-systems. Emergent behavior is inversely proportional to the degree of bondage between systems (the more tightly the component systems are coupled the less likely that the global emergent behavior will prevail; emergent behaviors do not arise in closed hierarchically structured systems), is non-linear and selforganized

The set of dynamical mechanisms whereby structures appear at the global level of a system from interactions among its lower-level components is emergent behavior
A.Dorofe eand other

G.Dyson

J.C.Hsu, M.Butter -field

C.Rouff and other 
We will assume that the software emergent properties are the randomly appear properties, that are displayed in the process of the software functioning during the subsystems interaction through interfaces, and if there are the specific data and the external influences:

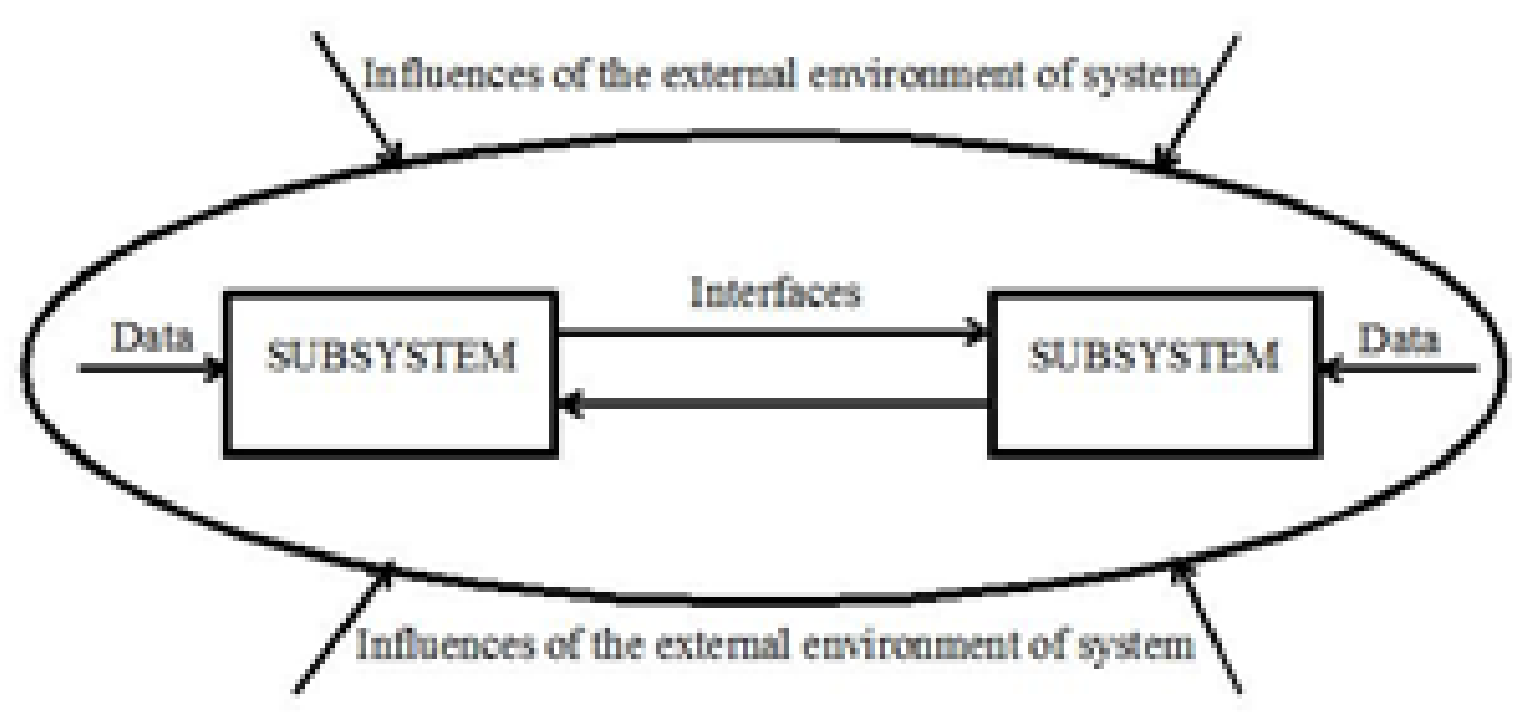

We will assume that the emergent behavior is the behavior of the software system, which is not typical to any separate subsystem, and emerges only during the interaction of subsystems; the developers didn't predict this behavior. 
The software incidents and accidents today include the new type of accident, that caused by the components interaction: each component has no defects, but incorrect intera
components leads to the problems:

\begin{tabular}{|c|c|c|c|c|c|}
\hline Event & Cause & Consequences & Event & Cause & Consequences \\
\hline $\begin{array}{c}\text { Explosion of rocket } \\
\text { Ariane } 5 \text { in } 1996\end{array}$ & $\begin{array}{l}\text { Mismatch of } \\
\text { requirements to } \\
\text { ensure reliability and } \\
\text { maximum allow-able } \\
\text { load }\end{array}$ & $\begin{array}{l}\text { The cost of } \\
\text { equipment and } \\
\text { development - } 7.5 \$ \\
\text { billion, "lost profits" } \\
-2 \$ \text { billion }\end{array}$ & $\begin{array}{l}\text { "Death" sessions of } \\
\text { radiation therapy } \\
\text { with Therac-25 in } \\
1985-1987 \text { [27] }\end{array}$ & $\begin{array}{l}\text { Incompleteness of } \\
\text { SRS; defects in the } \\
\text { development and } \\
\text { formulation of the } \\
\text { project; incorrect } \\
\text { assessment and } \\
\text { prediction of risks }\end{array}$ & $\begin{array}{l}6 \text { patients received a } \\
\text { lethal radiation dose }\end{array}$ \\
\hline Accidents of Mars & Defects in the project & $327.6 \$$ million - & & & \\
\hline $\begin{array}{c}\text { Climate Orbiter and } \\
\text { Mars Polar Lander in } \\
1999\end{array}$ & $\begin{array}{l}\text { through the use of } \\
\text { different } \\
\text { measurement units }\end{array}$ & $\begin{array}{c}\text { apparatus, } \\
91.7 \text { \$ million - } \\
\text { launch }\end{array}$ & $\begin{array}{l}\text { Failure in mobile } \\
\text { system of missile }\end{array}$ & $\begin{array}{l}\text { Rounding error that } \\
\text { was not critical at } \\
\text { the level of a single }\end{array}$ & $\begin{array}{l}28 \text { American soldiers } \\
\text { were killed and }\end{array}$ \\
\hline $\begin{array}{l}\text { Violation of flight of } \\
\text { launch vehicle of } \\
\text { Titan IV in } 1999\end{array}$ & $\begin{array}{l}\text { Error in software of } \\
\text { management system } \\
\text { of motor }\end{array}$ & $\begin{array}{l}\text { The loss of the } \\
\text { satellite Milstar }\end{array}$ & $\begin{array}{c}\text { defense "Patriot" in } \\
1991[27,28]\end{array}$ & $\begin{array}{l}\text { intensified during its } \\
\text { integration into the } \\
\text { system }\end{array}$ & $\begin{array}{c}\text { about } 100 \text { people } \\
\text { were injured }\end{array}$ \\
\hline $\begin{array}{c}\text { The crash of plane } \\
\text { «Superjet } 100 »\end{array}$ & $\begin{array}{c}\text { Incompatibility and } \\
\text { inconsistency of } \\
\text { software }\end{array}$ & $\begin{array}{c}\text { The death of } 48 \\
\text { people }\end{array}$ & $\begin{array}{l}\text { Falling into the } \\
\text { Pacific Ocean of } \\
\text { three satellites in } \\
2010[27,29]\end{array}$ & $\begin{array}{l}\text { Error in software } \\
\text { system integration }\end{array}$ & $\begin{array}{l}\text { The impossibility of } \\
\text { completing the } \\
\text { GLONASS }\end{array}$ \\
\hline
\end{tabular}


Today there are many approaches to detection of emergent properties of software systems:

1) the chronological approach as part of Software Process Improvement (SPI);

2) the comparison of software systems with natural groups with emergent behavior - for example, a group of migratory birds or ant colonies;

3) approaches and techniques from biological and social systems, physical sciences;

4) multi-agent formal methods: WSCCS, X-Machines;

5) UX-aware model for software requirements;

6) the use of the aspect-oriented programming technology;

7) semantic validation of emergent properties in component-based simulation models;

8) the use of service-oriented architectures (SOAs);

9) on the basis of the information model on SysML language;

10) on the basis of the use of the game theory;

11) the research agenda to deal with emergent misbehavior in complex software systems;

12) the use of system analysis. 


\section{Software quality models}

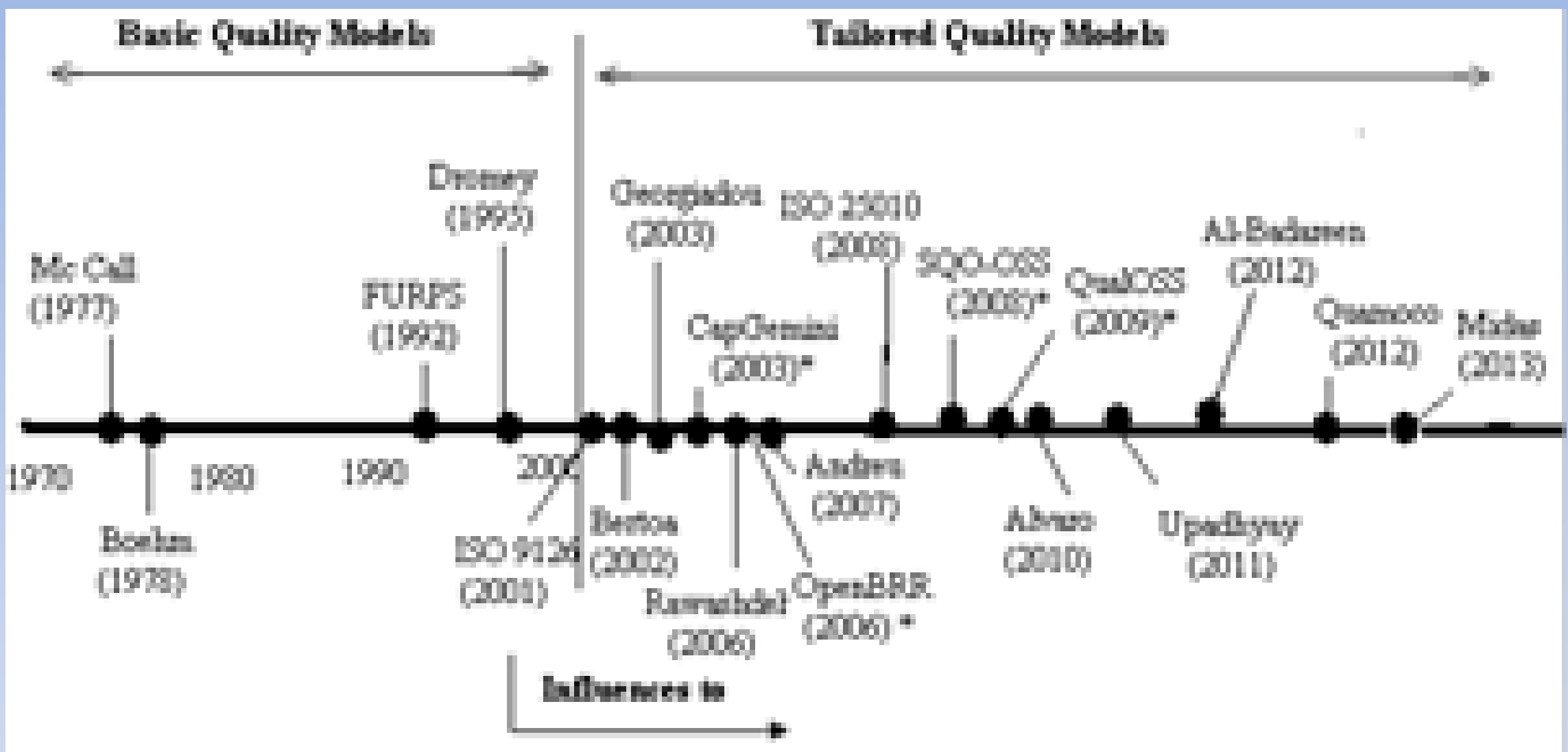

+ Q

The research of software quality models has shown, that nowadays they (especially Tailored Quality Models) weakly consider the systemic aspect of modern software. In particular the insufficient attention is paid to the software emergent properties. 
Correctness: traceability, completeness, consistency. Reliability: accuracy, error tolerance. Efficiency: execution efficiency, storage efficiency. Integrity: access control. Usability: operability, training, communicativeness. Maintainability: simplicity, conciseness, self-descriptiveness. Testability: simplicity, instrumentation, self-descriptiveness, modularity. Flexibility: selfdescriptiveness, expandability, generality. Portability: self-descriptiveness, software system independence, machine independence. Reuseability: machine independence, self-descriptiveness. Interoperability: modularity, communication commonality, data commonality

Portability: device independence, self-contentedness. Reliability: selfcontentedness, integrity, accuracy. Efficiency: accountability, accessibility. Human engineering: accessibility, communicativeness. Testability: structuredness, self-descriptiveness, accountability, accessibility, communicativeness. Understandability: legibility, conciseness, structured-ness, selfdescriptiveness. Modifiability: structured-ness, augment-ability

Functionality. Reliability. Maintainability. Efficiency. Reuseability. Portability Functionality: joint of characteristics, capacities, security. Usability: human factors, aesthetic, documentation of the user, material of training. Reliability: frequency and severity of failures, recovery to failures, time among failures. Performance: velocity, efficiency, availability, time of answers, time of recovery, utilization of resources. Supportability: testability, extensibility, adaptability, maintainability, compatibility, configurability, serviceability, instability, localizability

Functionality: suitability, accuracy, interoperability, security, functionality compliance. Reliability: maturity, fault tolerance, recoverability, reliability compliance. Usability: understandability, learnability, operability, attractiveness, usability compliance. Efficiency: time behavior, resource utilization, efficiency compliance. Maintainability: analyzability, changeability, stability, testability, maintainability compliance. Portability: adaptability, installability, co-existence, replaceability, portability compliance. Productivity. Safety. Satisfaction

ISO 25010 Functional Suitability: functional appropriateness, functional correctness, functional completeness. Reliability: maturity, availability, fault tolerance, recoverability. Performance efficiency: time-behavior, resource utilization, capacity. Compatibility: co-existence, interoperability. Usability: appropriateness recognisability, learnability, operability, user error protection, user interface aesthetics, accessability. Security: confidentiality, integrity, non-repudiation, accountability, authencity. Maintainability: modularity, reuseability, analyzability, modifiability, testability. Portability:

Functionality: accuracy, suitability, interoperability, compliance, security. Reliability: maturity, suitability. Usability: learnability, understandability, operability. Efficiency: time behavior, resource behavior. Maintainability: changeability, testability. Portability: replaceability

GEQUAMO Functionality. Usability: learnability, understandability, consistency

Alvaro

Functionality: accuracy, security, suitability, interoperability, compliance, self-contained. Reliability: recoverability, fault tolerance, maturity. Usability: configurability, understandability, learnability, operability. Efficiency: time behavior, resource behavior, scalability. Maintainability: stability, changeability, testability. Portability: deployability, replaceability, adaptability, reuseability

Rawashdeh Functionality: accuracy, security, suitability, interoperability, compliance, compatibility. Reliability: recoverability, maturity. Usability: understandability, learnability, operability, complexity. Efficiency: time behavior, resource behavior. Maintainability: changeability, testability. Manageability

CapGemini Integration: modularity, collaboration. Usability. Performance. Open

Source

Maturity

Model

OpenBRR

Model Reliability. Security. Platform independence. Vendor independence. Proven technology. Support. Interfacing. Reporting. Administration. Advise. Training. Staffing. Implementation

Functionality: compliance. Operational: transferability, security, usability. Support: service, training, consulting service. Documentation. Software Technology: portability, integration, modular and flexible. Community and adoption. Development process

SQO-OSS Maintainability: analyzability, changeability, stability, testability. Model

QualOSS Reliability: maturity, effectiveness. Security. Community Quality

Model Robustness and Elvovability. Maintainability. Security. Availability. Repeatability. Interactivity. Adequacy. Capability of requirements and change management. Capability of release management. Capability of support and community management 


\section{requirements in the software quality}

\section{models}

The non-functional requirements include the degree of internal indeterminacy (degree of subjectivity) and are formulated at the system level therefore they reflect some of the emergent properties of software systems.

The non-functional requirements [SWEBOK'2014]:

- quality

- complexity

- performance

- maintainability

- safety

- reliability

- security

- interoperability

- dependability 
Number of the non-functional requirements that are considered and evaluated by the software quality models:

Non-functional Software Quality Models (according to Table on Slide 10)



Quality

Complexity

Performance

Maintainability $x$

Safety

Reliability

Security

Interoperability $x$

$\begin{array}{llllllllllll}x & x & x & x & x & x & x\end{array}$

$\begin{array}{lllll} & x & & x & \\ x & x & x & x & x\end{array}$

$x$

Dependability

Total score

$\begin{array}{llllll}4 & 2 & 3 & 5 & 6 & 6\end{array}$

51

56

64

$\begin{array}{lll}4 & 2 & 4\end{array}$

3

All models ignore the important non-functional requirement "dependability".

There are three software quality models that can consider and evaluate the largest number of non-functional requirements (only 6 of 9 possible): ISO 9126, ISO 25010, Rawashdeh model. 


\section{Impact of the subject domain}

\section{information on the knowledge gap size}



Figure 1. The knowledge gap

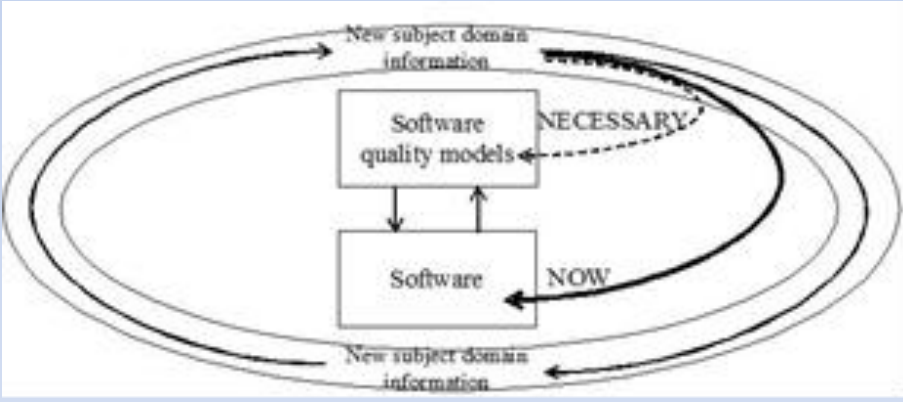

Figure 2. The detection of the emergent properties by consideration of the subject domain information in the software quality models

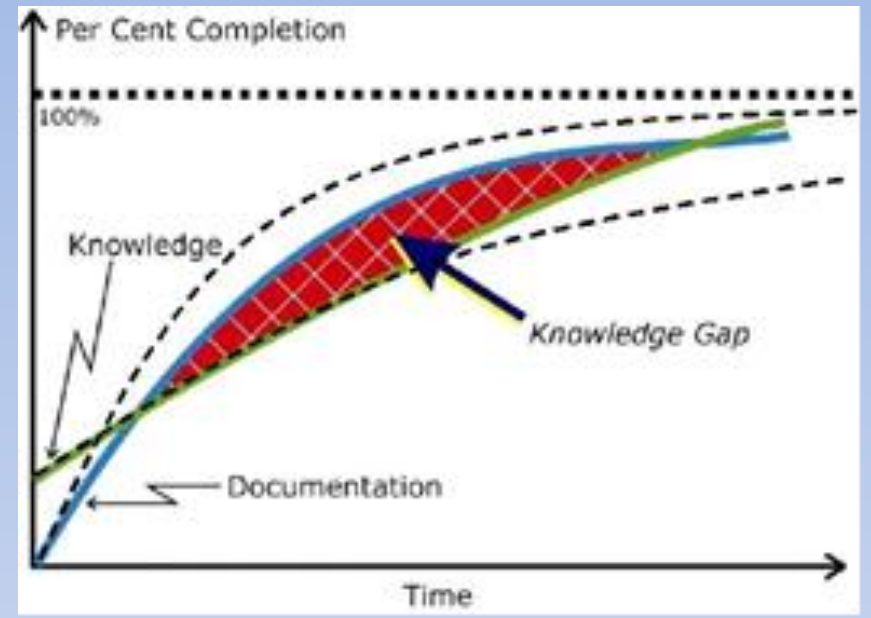

Figure 4.

Knowledge gap $\uparrow$ per cent Completion

with the consideration of the subject domain information in the software quality models (NECESSARY)
Figure 3 . The real size of the knowledge gap with nonconsideration of subject domain information in the software quality models (NOW) 


\section{Conclusions}

- The analysis of the known approaches to detection of emergent properties of software system and the analysis of the known software quality models testify that the significant share of current software quality problems is caused by the insufficient attention to the software emergent properties, to the consequences of their display and to the subject domain information that appears during software project life cycle.

- There has been active research in the explaining the nature of emergence of the emergent properties, but the software emergent properties are insufficiently formalized for their modeling and prediction.

- The effective methods and approaches for software emergent properties detection in principle were not developed. In general we need the fundamentally new approaches related to the full consideration of the subject domain information in the software quality models.

- The software quality models: don't consider the non-functional requirement "dependability»; consider and evaluate maximum 6 of 9 possible non-functional requirements (only 3 models). 
- The software quality models (especially Tailored Quality Models) are aimed at the evaluation and improvement of the quality of the separate components, and weakly consider the systemic aspect of modern software, and the insufficient attention is paid to the software emergent properties.

- Non-functional requirements reflect some of the software emergent properties, so we should maximize the ability of detection of nonfunctional requirements with the purpose of reducing the negative impact of emergent properties during the software exploitation.

- During software projects development there is gap of knowledge about the developed software characteristics. This knowledge gap emerges by reason of the partial consideration of the subject domain information in the software quality models. The size of knowledge gap is not constant for software project. The probability of disappearance of the knowledge gap during the software project life cycle is low, and the appearance of new subject domain information leads to increasing of the knowledge gap size.

- For safe software functioning the knowledge gap size is desirable to reduce with consideration of maximum subject domain information in the software quality models. 


\section{Our further research will focus on:}

1) the improvement of the software quality models in terms of the consideration and evaluation of the non-functional requirements, and in terms of the consideration of the subject domain information;

2) the identification of the share of emergent properties that are reflected in the non-functional requirements;

3) the increase of the share of the emergent properties that can be reflected in the non-functional requirements by means of the software quality models;

4) the development of methodology of software quality evaluation based on the development of methods and technologies of detection, evaluation and prediction of the software emergent properties on the basis of system analysis. 


\section{Questions \& discussion}

Thank you for attention! Questions, please!

Tetiana Hovorushchenko:

tat_yana@ukr.net

+38-095-11-22-544

skype: tat_yana_13

Oksana Pomorova:

o.pomorova@gmail.com

+38-067-384-17-50

skype: oksana.pomorova

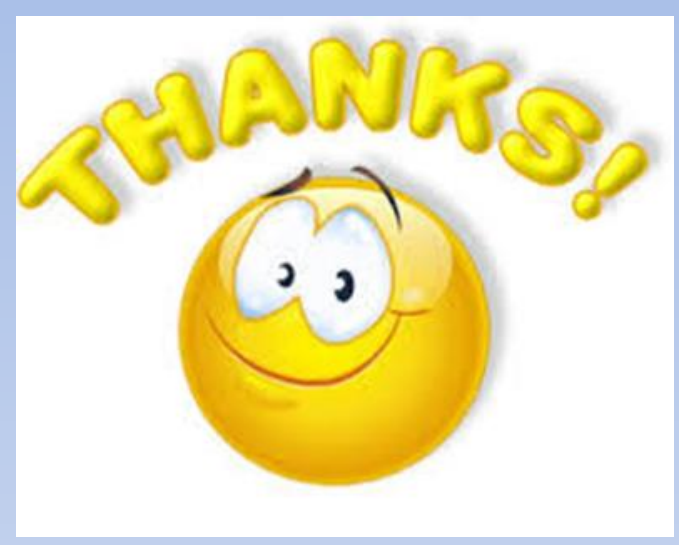

